Revista Iberoamericana. Vol. LXVI, Núm. 191, Abril-Junio 2000, 299-308

\title{
MANIFESTACIONES DEL JUDAÍSMO Y COLONIZACIÓN DE LO IMAGINARIO EN IBEROMÉRICA DURANTE LA PRIMERA FASE MODERNA DEL IMPERIO ESPAÑOL ${ }^{1}$
}

\author{
POR \\ Lúcia Helena Costigan \\ The Ohio State University
}

I.

En su obra, O Mediterrâneo e o Mundo Mediterrânico na época de Filipe II, Fernand Braudel compara la cultura judaica con pequeñas gotas de aceite en las profundas aguas de otras civilizaciones. Este aceite jamás se disuelve ni es totalmente absorbido. ${ }^{2}$

La metáfora utilizada por Braudel es muy oportuna para situar al cristiano nuevo ${ }^{3}$ en el contexto metropolitano y colonial durante los siglos XVI y XVII. La cultura europea dominante fomentó el proceso de occidentalización en esta época. En su primer impulso de occidentalización la cultura hegemónica europea buscó eliminar todo aquello que no compartía su concepto cristiano del mundo. El estudio de Lucien Febvre sobre Le problème de l'incroyance au XVIe. siècle: La religion de Rabelais demuestra la intolerancia de la cultura cristiana del siglo XVI. Al exponer las persecuciones a François Rabelais por su aparente falta de fe, Febvre cuestionó el concepto humanista y la empresa universal de la religión cristiana del dieciseis, siglo visto como uno de los más avanzados en la historia de la humanidad. Lejos de ver a Rabelais como a un ser sin fe, el crítico-historiador francés lo vió como a un creyente "más allá de su tiempo". ${ }^{4}$

Por vivir en la época de la Reforma y de la Contrarreforma, Rabelais optó por un modo de pensar y de vivir más cerca de la influencia de Erasmo que del cristianismo oficial. Al

\footnotetext{
${ }^{1}$ Agradezco a Alicia Chaves por ayudarme a evitar la influencia del Portugués en el texto. También agradezco a Carmen Tesser y a Manuel Gómez-Fernández por las sugerencias.

2 “...os judeus, onde quer que estejam, surgem ao historiador como muito capazes de se adaptarem ao meio ambiente.(...) Seguramente uma civilização . A matéria de que se compõe esta civilização parece dispersa, espalhada como múltiplas finas gotinhas de azeite sobre as águas profundas de outras civilizações e nunca confundidas, ainda que sempre dependentes delas” (Braudel 165-166).

${ }^{3}$ Las palabras "cristiano nuevo" y "converso" usadas en este texto se refieren a descendientes de judíos portugueses y españoles bautizados en masa a finales del siglo XV. A su vez, los términos “criptojudío” o “marrano” implican que las personas así nombradas mantenían costumbres y prácticas judaizantes.

4 “Et 'voici venu le moment d'nterroger Rabelais, Rabelais lui-même’—c'est-à-dire son æuvre. Et le lecteur voit se dessiner peu à peu un Rabelais étonnant de vie et de vérité, bien de son siècle et cependant très "avancé" pour son siècle: croyant, il est en lutte ouvert avec toutes les superstitions des 'pauvres idiots' qui l'entourent” (Febvre 9).
} 
analizar el caso rabelaisiano y las controversias alrededor de las obras Pantagruel (1532) y Gargantua (1534) Febvre captó el lado positivo y negativo del siglo renacentista y probó que las persecuciones sufridas por el libre pensador francés ocurrieron porque su compromiso con la verdad lo hizo vivir en lucha abierta contra las supersticiones de su medio ambiente. El ejemplo de Rabelais sirve para ilustrar la intransigencia religiosa de la cultura occidental dominante durante los siglos XVI y XVII. Al situar a Rabelais en el contexto imperial en que vivían Bento Teixeira (1561?-1600) y Luis de Carvajal (1567-1696) —letrados criptojudíos perseguidos por la Inquisición durante el reinado de Felipe II- podemos percibir el riesgo que implicaba el expresar ideas y creencias diferentes de las normas estamentales en vigor en el contexto europeo durante la alborada de la edad moderna.

La fecha oficial de la primera fase del colonialismo moderno del imperio español estuvo marcada por el deseo del “descubrimiento”, pero también por la intolerancia hacia las diferencias étnicas y religiosas. Basta recordar que 1492 fue la fecha del primer viaje de Colón, y también la de la expulsión de los moros de Granada y de los judíos de Barcelona. Estos hechos marcaron el fin de la tolerancia religiosa, pero no el fin del judaísmo en los dominios del imperio español.

A partir de 1492, para escapar a las persecusiones de los Reyes Católicos y al antisemitismo ${ }^{5}$ de las masas, tanto en la Península como en las colonias, los judíos que optaron por quedarse en los dominios españoles se vieron forzados a asumir una identidad que les fue impuesta: la de conversos o cristianos nuevos. Sin embargo, muchos de los judeocristianos rechazaron gradualmente la nueva condición impuesta, cuando los prejuicios y exclusiones corrientes de la revisión del estatuto de puritatis sanguinis, —encabezada por el arzobispo Juan Martínez Silício y apoyada por Felipe II- ${ }^{6}$ dieron lugar a una personalidad híbrida y traumática. Según lo que postula Esther Benbassa en su obra Memoires juives de Espagne y du Portugal, a partir de finales del siglo XVI, y a lo largo de todo el siglo XVII, las generaciones de cristianos nuevos que habían mantenido un saber popular colectivo empezaron a asumir la identidad clandestina criptojudía o marrana. La recuperación de la memoria e identidad judía ocurrió de manera voluntaria y gradual, ${ }^{7}$

\footnotetext{
${ }^{5}$ El uso de las palabras "antisemitismo" y "antisemítico" para describir la actitud discriminatoria de los cristianos viejos contra los cristianos nuevos o conversos es un anacronismo. Estamos de acuerdo con Yosef Hayim Yerushalmi, cuando él afirma en su obra From Spanish Court to Italian Ghetto: "I have, however, frequently referred to Iberian 'antisemitism' and 'antisemites' well aware that such nineteenth-century terms are essentially anachronistic, and perhaps especially so in the Peninsula, where, in the period we are discussing, there were formally no Jews” (xvi).

${ }^{6}$ Albert A. Sicroff se basa en fuentes primarias para documentar la intensificación del movimiento anti-converso en los dominios imperiales españoles a partir de mediados del siglo XVI. En el capítulo III de la obra Les controverses des statuts de "pureté de sang"en Espagne du XVe. au XVIIe. siècle, Sicroff documenta la consagración oficial de la "limpieza de sangre" por el estado y por la iglesia españoles durante la regencia de Felipe II: “...Ainsi, Silício obtint un certain prestige (...) qui le conduisit finalement au siège primatial d’Espagne (1546), ascension dont le préceptorat du Prince Philippe, qu'il exerça dix ans, fut l’origine” (96). La consagración de la "limpieza de sangre” ocurrió a través de leyes que prohibían a los candidatos sospechos, de sangre judía o mora, "pas que même une remeur-fût-elle fausse” (97) la ocupación de cargos eclesiásticos y civiles.

${ }^{7}$ En las palabras de Benbassa: "Le retour au judaïsme de la troisième génération de nouveaux chrétiens, surtout à partir du XVe. siècle, est formulé soit comme conversion soit comme continuité avec une judéité clandestine...” (7).
} 
desafiando, así, lo que Serge Gruzinski describe como “la colonización de lo imaginario”, emprendida por "la España conquistadora del imperio de Carlos V” (La colonización 77) y de su hijo, Felipe II, durante la primera fase de la modernidad.

De manera análoga a los androides de la película Blade Runner de Ridley Scott, los cristianos nuevos que ocupaban cargos de prestigio en la sociedad española pasaron a ser vistos como "replicantes" amenazantes del status privilegiado de los cristianos viejos. Frente a tal amenaza, se buscó eliminarlos o "retirarlos". 8 Paradójicamente, el trauma provocado por las discriminaciones y persecuciones llevó a los peninsulares de origen hebreo a tratar de olvidar su condición de cristiano nuevo y a recuperar su memoria y antigua condición judía. Para los cristianos nuevos en la diáspora desde finales del siglo XV hasta el XVIII, el proceso simultáneo de tentativa de olvido de un presente traumático y de búsqueda de un pasado judío feliz, en combinación con el arraigo a la cultura peninsular, resultó en una identidad híbrida, “mi-iberique mi-biblique” (75), como describe Daniel M. Swetschinski en su estudio de la diáspora de los judíos portugueses de Amsterdam. ${ }^{9}$

II.

En este apartado buscaré delinear la experiencia del cristiano nuevo sefardita imigrado a las colonias de la América y la posición del mismo frente a la "colonización del imaginario”, observada desde la segunda mitad del siglo XVI en adelante. Como prototipos de descendientes de judíos peninsulares que emigraron al Nuevo Mundo durante el período en cuestión, tomaremos como ejemplos a Bento Teixeira y a Luis de Carvajal.

Como han documentado algunos estudiosos de la historia de los judíos y cristianos nuevos en las colonias españolas y portuguesa de América, entre los cuales, Seymour B. Leibman, Arnold Wiznitzer y José Gonçalves Salvador, ${ }^{10}$ muchos cristianos nuevos buscaron y lograron el mejoramiento de su condición social en tierras americanas durante las primeras décadas de la colonia. El cronista y misionero Fernão Cardim documentó sus impresiones sobre el ambiente social en la región noroeste de la colonia portuguesa a mediados del siglo XVI. Según él, los habitantes de la región de Pernambuco mostraron mayor lujo y riqueza que los de Lisboa, capital del imperio lusitano. La tendencia barroca hacia lo efímero y mundano del carpe diem es evidente en la vanidad y en la aparente falta de fé cristiana de las mujeres locales, según deducimos de la descripción de Cardim: “As mulheres são muito senhoras, e não muito devotas, nem frequentam as missas, pregações, confissões, etc. Vestem-se (...) de toda sorte de veludos, damascos e outras sedas, e nisto

\footnotetext{
${ }^{8}$ Utilizo aquí una expresión empleada por Gruzinski para referirse al proceso de substitución de las imágenes “defectuosas" de los nativos de México por las imágenes barrocas del cristianismo contrarreformista. La llamada "guerra de las imágenes” ganó ímpetu en la Nueva España a partir del concilio de 1555, encabezado por el teólogo granadino Alonso de Montúfar. Ver La guerra de las imágenes (154).

${ }^{9}$ Swetschinski explica que los judíos portugueses de Amsterdam tenían una identidad híbrida: “miibérique, mi-biblique, parce qu' une identité vraiment ibéro-juive ou judéo-iberique ou même simplement juive ne pouvait pas s'extraire du passé marrane” (75).

${ }^{10}$ Véase Seymor Liebman, Arnold Wiznitzer y José Gonçalves Salvador, Os cristãos-novos: povoamento e conquista do solo brasileiro, 1530-1680.
} 
têm grandes excessos” (154). En el México de la misma época, vemos un efecto de mundanidad renacentista y barroca similar a la que los cronistas y misioneros registraron sobre la sociedad colonial del noroeste brasileño. Esto puede ser comprobado con la siguiente descripción del frayle Vicente de Santa María: “Parece que el Nuevo Reino de León era el estómago donde se digerían las malignas especies de sedición cuya acrimonia trascendía el cuerpo de aquellas fronteras” (5).

Si en su obra Baroque Times in Old Mexico Irving Leonard nos hace visualizar la efusión barroca de la capital de la Nueva España, donde las supersticiones convivían con la religión y el lujo de las procesiones glamorosas contrastaba con la violencia de los autos de fe, Solange Alberro nos hace percibir la complejidad de los pueblos y regiones alejadas del virreinato, donde el culto contrarreformista de la imagen cristiana se había desplazado y se ejercía en el interior mismo de la sociedad colonial, y que puede ser observado cuando "las mujeres... borda[ban] el nombre de María sobre sus camisas, lleva[ban] las imágenes de la Inmaculada y del Santísimo ... en sus trenzas, sobre la cabeza, en el pecho ...[y] agasaja[ban] a los huéspedes con chocolate y santos de dulces” (Alberro 384).

La efusión barroca del México colonial no se limitó a los grupos cristianos. El matchmaking que ocurría entre los pueblos de origen judío también se hace patente en la tendencia a lo mundano de la cultura barroca. En su relato autobiográfico titulado Memorias, Luis de Carvajal documentó el cambio social en la vida de sus hermanas, cuando ricos criptojudíos fueron enviados al Nuevo Reino de León con la misión de casarse con ellas. La costumbre judía del match-making, además de evitar que ellas se casaran con cristianos, permitió con que salieran de Pánuco, lugar inhóspito donde vivían y se trasladaran a la capital del virreinato. Lograron así, mejorar su posición socioeconómica y mantener sus creencias y principios milenarios:

Estando Joseph en aquella villa acabo ya de dos años, su madre, y hermanas, y hermanos en el destierro dicho de Pánuco, todas con luto, y tristeza de la muerte de su padre, que como queda dicho avia poco que era muerto, entendiendo segun via humana, que por esto tubieran las huérfana mas tardio remedio, aviendo procurado el ceigo de su tio casarlas, o ponerlas de lado con soldados y capitanes gentiles, lo cual con mucho temor el sr.'mientras vivió, avia resistido el refunto padre, atendiendo a su smo. mandato en que lo prohibe: antes de aver quitado el luto y pasando alli tanta pobreza que algunas dellas andubieron harto tiempo descalzas y bien mal vestidas sirviendo virtuosamente a su madre en vida honesta y recojida, estando un día bien descuidadas, oyeron de repente chirimias, y trompetas a sus puertas, y era la causa haber llegado a su casa dos maridos que el Señor enviaba a las huérfanas temerosas suyos y de su pueblo, ricos y llenos de bienes, muy bien aderezados y con sedas, cadenas de oro al cuello, .a los quales movio para venir a hazer esta buena obra el D. del cielo, pues a solo casarse con las huérfanas llevando muchos vestidos y dones a ellas., y a su madre avían venido setenta leguas que ay de camino desde Pánuco a México para donde se vinieron despues de las bodas celebradas con grande gozo no solo de ellas, sino de los estraños, los quales espantados del suceso y dando el parabién a la dichosa madre muchas de las gentílicas mujeres le decían: ¿Señora, y que buena oración rezasteis? (Carvajal 467-468)

A partir de la Contrarreforma, la situación de los cristianos nuevos se hizo complicada con el establecimiento del Santo Oficio en México, en 1571, y con la incorporación de 
Portugal y de sus posesiones ultramarinas al imperio español, en 1580. Felipe II no logró implantar el Tribunal del Santo Oficio en Brasil debido a la oposición de los jesuítas y de los gobernadores generales (véase Salvador, Os cristãos-novos). Empero, en 1591, las visitaciones materializaron la presencia de la Inquisición con la llegada de Heitor Furtado de Mendonça, eclesiástico de confianza del monarca español.

Heitor Furtado de Mendonça oyó y registró confesiones y denuncias en Bahía durante su primera visita del Santo Oficio al noroeste del Brasil. Fue entonces cuando el nombre de Bento Teixeira entró en las páginas inquisitoriales. En enero de 1594, cuando el visitador llegó a Pernambuco, Bento Teixeira fue obligado a comparecer ante los oficiales del Santo Oficio. Para defenderse de las acusaciones de judaizante, Bento Teixeira escribió una larga confesión para eximirse del crimen. Según lo que se deduce de su proceso inquisitorial, él asesinó a su mujer porque temía que ella lo iba a denunciar a los visitadores de la Inquisición. En la confesión escrita que el reo entregó al visitador en 1594, él afirmó que los amantes de la mujer que él asesinara por traidora fueron quienes lo denunciaron al Santo Oficio. “ E pela [falta] da experiencia que então não tinha ... e preso do lascivo amor de uma Filipa Raposa...me casei com ela, sendo a dita tão nobre em geração como em seus próprios vícios, a qual foi a fonte donde se originaram meus trabalhos e a prisão que de presente padeço...”. ${ }^{11}$

A pesar de su vehemente defensa, el reo no logró convencer a los inquisidores de que no practicaba en secreto la religión de sus antepasados. Se le apresó el día 29 de agosto de 1595 como sospechoso de practicar el judaísmo. El año siguiente, 1596, fue enviado a la cárcel de la Inquisición en Lisboa. Bento Teixeira participó en un acto de fe el 31 de enero de 1599, donde, aparentemente, se mostró arrepentido y renunció al judaismo. Antes de morir de tuberculosis, en 1600, escribió un poema épico titulado Prosopopéia. En este poema elogió a los descendientes de los judíos sefarditas, indirecta y metafóricamente.

Luis de Carvajal, el Mozo, converso letrado que emigró al virreinato de la Nueva España en su adolescencia, se convirtió en víctima de la Inquisición mexicana en 1589. Fue acusado de haber regresado al judaísmo. La relación de Luis de Carvajal con el Tribunal del Santo Oficio comprende dos etapas y dos procesos distintos. El primero se inicia con la prisión del reo el 9 de mayo de 1589 y termina el 8 de noviembre del mismo año. Según el relato de los oficiales del Santo Ofício, Carvajal se arrepintió de haber abrazado la Ley de Moisés y participó del acto de fe realizado en la capital del virreinato el 8 de noviembre de 1589. A pesar de su aparente reconciliación con la Iglesia Católica, la memoria fragmentada de su condición conversa o marrana lo llevó a abrazar definitivamente el judaísmo. Acusado por uno de sus correligionarios, la Inquisición le encarceló el 1 de febrero de 1596. Esta vez pagó con su vida la herejía, el relapso y la apostasía.

Las obras literarias producidas por Bento Teixeira y Luis de Carvajal integran lo que Thomas Cohen clasifica como "discurso mesiánico y profético" en oposición a la política imperial de los Habsburgos de España. ${ }^{12}$ Tanto Carvajal como Bento Teixeira profetizaban

\footnotetext{
${ }^{11}$ Esa y las demás declaraciones de Bento Teixeira se encuentran en el Processo 5.206 da Inquisição de Lisboa, del Arquivo Nacional da Torre do Tombo, en Lisboa. Dejo de incluir el número de la página porque las mismas no están debidamente numeradas.

${ }^{12}$ En The Fire of Tongues, Thomas Cohen afirma: "The subject of Habsburgh rule has been inadequately investigated, in relation not only to the Portuguese Empire but also to the metropolis (...) including messianic and millenarian literature and the roles of the Jesuits and New Christians in the opposition to Habsburgh rule ...” (51-52).
} 
el triunfo de los judíos y cristianos nuevos bajo el poder de los emperadores españoles. A pesar de haber participado en el proceso de occidentalización del Nuevo Mundo, Carvajal y Bento Teixeira no sucumbieron a la “colonización de lo imaginario”. Los escritos apócrifos y algunas de las declaraciones incluídas en los procesos inquisitoriales revelan que esos dos letrados criptojudíos trataron de mantener su herencia sefardita y de resistir la uniformización religiosa. La resistencia de los cristianos nuevos se situaba dentro de lo que Braudel consideró como "as armas do mais fraco: a resignação, os distinguo talmúdicos, a astúcia, a obstinação, a coragem, até o heroísmo” (165). Por otro lado, la actitud que ellos denunciaron entre líneas cuestionaba el concepto del humanismo del dieciseis, siglo que como propuso Lucien Febvre: “... c’est tout un siècle à repenser [y cuya concepción humanista] se trouve remise en cause” (23). En su obra The Darker Side of the Renaissance, Walter Mignolo también cuestionó la conceptualización humanista de la cultura europea renacentista durante la conquista y colonización del Nuevo Mundo. Semejante a lo que estudió Febvre con respecto a Rabelais y al ambiente europeo del siglo XVI, Mignolo analizó las políticas literarias y territoriales europeas en el contexto hispanoamericano de la primera fase del colonialismo moderno del imperio español, poniendo en evidencia "the legacies of the 'darker side of the Renaissance'”(viii-ix).

La producción de Bento Teixeira y de Luis de Carvajal revela la intención de persuadir a los inquisidores sobre la incoherencia de la persecución a los cristianos nuevos. Vemos el argumento de Bento Teixeira en las palabras que dirige a sus inquisidores: “... se Deus nosso Senhor foi servido que meu pai fosse cristão-novo ... que culpa tenho eu?” (Proceso 5.206). Esta pregunta desenmascara la arbitrariedad y la arrogancia de las autoridades político-eclesiásticas de la época, y revela que Bento Teixeira asumía la identidad étnicocultural hebrea. La respuesta que él dió a sus perseguidores confirma esta aserción: "Se antes que eu nascesse me perguntassem qual queria: ser filho de cristão-velho ou de cristão novo ... eu por minha eleição tornaria ser filho de cristão-novo” (Proceso 5.206).

Del mismo modo, en Memorias, Luis de Carvajal aceptaba su condición judaica y cuestionaba los dogmas del cristianismo católico cuando afirmaba que: “... creo que la Ley de Dios Nuestro Señor que los cristianos llaman muerta de Moisés, es viva y sin fin, como consta de todo el Sagrado Pentateuco (...) y lo que dicen los cristianos que los preceptos ceremoniales y judiciales son muertos y que ya expiraron es contra uno de sus mismos evangelios” (413). Tanto en Carvajal como en Bento Teixeira percibimos un mensaje judaico de resistencia al proyecto cristiano de colonización del imaginario.

Memorias documenta la historia de la persecución de los adeptos a la ley de Moisés en el virreinato de la Nueva España. La voz del narrador omnisciente converge con la del protagonista, haciendo que el lector identifique la historia de Carvajal con la de José Lumbroso, o sea, con la del personaje bíblico José, vendido como esclavo a los egípcios, pero que logró salvarse de su cautiverio, transformándose en líder de los hebreos. Al asociar su vida con la de José, Carvajal veía la diáspora de los sefarditas en México como un cautiverio: “y como por agora por estar el que esto ha escrito todavía en tierras de captiverio, aunque en vísperas de salir con la ayuda y favor del altísimo y fuertísimo, A. D. de Ysrael ... Por lo qual humillo mi corazón. Adoro y glorifico a su santísimo nombre y confieso que es bueno y máximo y que es eterna su misericordia, la qual no valga y a todo Ysrael, amén” (Procesos 495-496). Como confesión autobiográfica ficcionalizada, Memorias funcionó 
como una catarsis. Permitió que Carvajal se liberara de su identidad de cristiano nuevo y se trasformara, mediante la escritura, en la persona/personaje judío de José Lumbroso. Comparada con Memorias de Carvajal, el poema Prosopopéia de Bento Teixeira también puede ser interpretado como una catarsis. El poeta creó su obra a partir del olvido y del recuerdo. Buscó olvidar los sufrimientos provocados por su experiencia traumática de cristiano nuevo y trató de recuperar la memoria feliz de un pasado judío que le había sido transmitido por su madre. A partir del intento de olvidar el presente y de recuperar la memoria colectiva del pasado judío Bento Teixeiral se ficcionalizó, transformándose en Proteo, héroe de su poema épico. La figura camaleónica y camuflajeada de Proteo encuentra correspondencia tanto en la representación alegórica del poeta, como en la del cristianonuevo que gradualmente retornaba al judaísmo. Al igual que Proteo, manipulador de formas, el vate criptojudío utilizó su talento artístico para moldear su lenguaje, dar significados diferentes a las palabras y poder, así, enviar mensajes de ánimo a sus correligionarios:

Vem o Velho Proteu, que vaticina

(Se damos fé à velha antiguidade)

Os males a que a sorte nos destina,

Nascidos da mortal temeridade

Vem numa e noutra forma peregrina,

Mudando a natural propriedade

Não troque a forma, venha confiado,

Se não quer de Aristeu ser sojigado (29).

- Companheiros leais, a quem no Côro

Das Musas tem a fama entronizado,

Não deveis ignorar, que não ignoro,

Os trabalhos que haveis no Mar passado

Respondestes 'té 'gora com o fôro,

Devido a nosso Luso celebrado,

Mostrando-vos mais firmes contra a sorte

Do que ela contra nós se mostra forte (59).

La hipótesis de que el poema épico de Bento Teixeira sea una manifestación y reacción de los criptojudíos contra la política antisemita de los Habsburgos de España, puede ser fundamentada a través de su proceso inquisitorial. En una de las confesiones escritas que Bento Teixeira tuvo que entregar a los inquisidores para evitar la muerte en la hoguera, se encuentra una carta escrita en código, de la cual se destaca el siguiente pasaje:

Sabereis que o nosso Troiano é na realenga a negociar com a Águia do Bico Revolto, aquilo de que menos temos e de que mais havemos necessidade (...) Estes anos atrás, mandou a Águia voante visitar a alfândega real, as trevas exteriores e o cano real por o Bogio manco, que no tempo de Sebasto, foi letra do A, B, C português, e tal seja a sua vida e saúde, qual foi a visitação que se muitos fardos se tomavam por perdidos dantes, mais se toma agora depois dele visitar. 

leían:

Según Bento Teixeira, los letrados criptojudíos que decodificaban el texto al Portugués

\begin{abstract}
Haveis de saber que o nosso Heitor Mendes é na corte de Madrid a negociar nossa liberdade com El-Rei Felipe (...) Estes anos atrás, mandou El-Rei Felipe visitar as inquisições deste reino, a saber: a de Lisboa, a de Évora e Coimbra, as quais visitou Martim Gonçalves da Câmara, que em tempo dEl-Rei Sebastião governou o reino todo. E tal seja a sua saúde e vida, qual foi a visita que el fez, que se antes disto prendiam muita gente da nação, muito mais prendem agora e penitenciam.(...) Rogai todos aos Senhor Deus, que encaminhe e ordene todas as nossas coisas bem e suavemente.
\end{abstract}

Como se puede observar, la carta revela la existencia de un código secreto de comunicación escrita usado por los cristianos nuevos diasporados en Europa y en el Nuevo Mundo. También, B. Teixeira sugería que el emperador Felipe II representaba a un enemigo de los cristianos nuevos y judíos, al afirmar que "muito mais prendem agora e penitenciam muita gente da nação”, que durante el reinado del rey portugués, Dom Sebastião, remplazado por el emperador Felipe II, dos años después del desaparecimiento del rey lusitano en la gran batalla de Alcácer Quibir, ocurrida en 1578.

La crítica de Luis de Carvajal contra el emperador español fue abierta, como observamos en el comentario que el letrado de Nueva España escribió en su “Testamento”:

\begin{abstract}
... creo que aquel rey Antioco, a quien la Sagrada Escritura llama raíz de pecado, por ser perseguidor del pueblo de Dios y de su Santa Ley, y fue figura de los Reyes de España y Portugal, los cuales han sido y son la raíz de que han procedido y proceden los ramos de las inquisiciones y persecuciones del pueblo de Dios Nuestro Señor y de su Santa Ley, y de los bienaventurados mártires, que son los fieles y verdaderos judíos que mueren por la fe de ella, a quienes los príncipes que sin causa los persiguen llaman injustamente herejes judaizantes, porque judaizar no es herejía ... (Procesos 416)
\end{abstract}

Proponemos que el cristiano nuevo de México se refiere al Rey Felipe II, en su comentario testimonial. Al referirse a los reyes “de España y Portugal” usando el verbo ser en el presente del indicativo, Carvajal comparó implícitamente al emperador de España y Portugal con Antioco IV, rey asirio que en la era pre-cristiana esclavizó a los israelitas, forzándolos a sustituir el altar de Jehová por el de Zeus, intentando así prohibirles ser judíos.

Como espero haber demostrado, a través del estudio del caso de Bento Teixeira y de Luis de Carvajal, el discurso del cristiano nuevo letrado, constituido por textos literarios y confesiones inquisitoriales, evidencia un sujeto colonial como agente activo en el proceso de occidentalización del Nuevo Mundo, pero también señala su resistencia a la colonización de lo imaginario. En el contexto del colonialismo moderno del imperio español, el gran mérito de este grupo étnico fue el de integrarse a la cultura occidental, sin dejarse aplastar por ella. La metáfora de Braudel donde compara la cultura judaica con gotas de aceite que no se disuelven en el agua de otras civilizaciones explica la defensa de su etnia y cultura en el proceso de occidentalización del Viejo y del Nuevo Mundo. 
BiBLIOGRAFÍA

Alberro, Solange. Inquisición y sociedad en México,1571-1700. México: Fondo de Cultura Económica, 1988.

Benbassa, Esther (ed.). Memóires juives d'Espagne et du Portugal. París: PUBLISUD, 1996.

Braudel, Fernand. O Mediterrâneo e o Mundo Mediterrânico na época de Filipe II. [1966]. Lisboa: Publicações Dom Quixote, 1984.

Cardim, Fernão. Tratados da terra e da gente do Brasil. [1881]. Belo Horizonte/São Paulo: Editora Itatiaia, 1980.

Cohen, Thomas. The Fire of Tongues. António Vieira and the Missionary Church in Brazil and Portugal. Stanford: Stanford University Press, 1998.

Fevbre, Lucien. Le problème de l'incroyance au XVIe. siècle: La religion de Rabelais. [1942] 2.ed. Paris: Éditions Albin Michel, 1968.

Grunzinski, Serge. La colonización de lo imaginario: Sociedades indígenas y occidentalizació en el México español. Siglos XVI-XVIII. [1988]. México: Fondo de Cultura Económica, 1991.

La guerra de las imágenes:de Cristóbal Colón a “Blade Runner” (1492-2019). [1990]. México: Fondo de Cultura Económica, 1994.

Irving, Leonard G. Baroque Times in Old Mexico. [1959]. Ann Arbor: The University of Michigan Press, 1966.

Liebman, Seymour B. New World Jewry, 1493-1825: Requiem for the Forgotten. Nueva York: Ktav Publishing House, Inc., 1982.

Mignolo, Walter D. The Darker Side of the Renaissance: Literacy \&Territoriality. Ann Arbor: University of Michigan Press, 1995.

Processo 5.206 da Inquisição de Lisboa. (Microfilm 633) Arquivo Nacional da Torre do Tombo, Lisboa.

Procesos de Luis de Carvajal (El Mozo). México: Publicaciones del Archivo General de la Nación, 1935.

Salvador, José Gonçalves. Os cristãos-novos: povoamento e conquista do solo brasileiro (1530-1680). São Paulo: Livraria Pioneira Editora, 1976. Os cristãos-novos e o comércio no Atlântico meridional (con enfoque nas capitanias do Sul, 1530-1680). Brasília: Instituto Nacional do Livro, 1978.

Santa María, Fr. Vicente de. “Estado de Nuevo León”. Reseña Geográfica y Estadística. París/México: Librería de la Viúda de C. Bouret, 1908. 9.

Sicroff, Albert A. Les controverses des statuts de 'pureté de sang' en Espagne du Xve. au XVIIe siècle. París: Librarie Marcel Didier, 1960.

Swetschinski, Daniel M. "Un refus de mémoire: Les juifs portugais d’Amsterdam et leur passé marrane”. Mémoire Juives d'Espagne et du Portugal. Esther Benbassa, ed. Paris: PUBLISUD, 1996. 69-75.

Teixeira, Bento. Prosopopéia [1601]. Celso Cunha y Carlos Duval, Introd., ed. y comentarios. Rio de Janeiro: Instituto Nacional do Livro/MEC, 1972.

Wiznitzer, Arnold. Os judeus no Brasil colonial. São Paulo: Pioneira, 1966. 
Yerushalmi, Yosef Hayim. From Spanish Court to Italian Ghetto. Isaac Cardoso: A Study in Seventeenth-Century Marranism and Jewish Apologetics. [1971]. Seattle/Londres: University of Washington Press, 1981. 